\title{
DISTRIBUIÇÃO ESPACIAL DOS DEPÓSITOS SEDIMENTARES ALUVIONARES E SUAS RELAÇÕES COM O PROCESSO DE EVOLUÇÃO DA REDE DE DRENAGEM NO MÉDIO VALE DO PARAÍBA DO SUL - RJ/MG
}

\author{
Stephany Emiliane Lopes da Silva ${ }^{(a)}$, Raphaela Almeida de Souza ${ }^{(b)}$, Rodrigo Wagner Paixão \\ Pinto $^{(\mathrm{c})}$, Marcelo Motta de Freitas ${ }^{(\mathrm{d})}$ \\ (a) Departamento de Geografia e Meio Ambiente, PUC-Rio (stephany-emiliane@hotmail.com) \\ (b) Departamento de Geografia e Meio Ambiente, PUC-Rio (raphaelaalmeidas@yahoo.com.br) \\ (c) Departamento de Geografia e Meio Ambiente, PUC-Rio (rodrigowpp1@gmail.com) \\ (d) Departamento de Geografia e Meio Ambiente, PUC-Rio (marcelomotta@ puc-rio.br)
}

\section{EIXO: SISTEMAS GEOMORFOLÓGICOS:ESTRUTURAS, DINÂMICAS E PROCESSOS}

\begin{abstract}
Resumo
A separação do continente Gondwana e seus múltiplos eventos até a consolidação do Rift Continental Sudeste implicou em uma mudança significativa no relevo sudeste e, consequentemente, nos sistemas de drenagens. Como representante de tais processos esta pesquisa recai sobre o estudo de um afluente do rio Paraíba do Sul, cujo sistema fluvial é constituído pelas drenagens entre o rio Macuco e rio Minerva que apresentam expressivos depósitos fluviais. A metodologia utilizada buscou compreender a evolução do relevo na bacia do rio Minerva, por meio do levantamento de evidências de depósitos fluviais em níveis topográficos diferentes e da relação entre aspectos geológicos e geomorfológicos na organização de sua rede de drenagem. Durante o mapeamento pôde-se observar disposição de depósitos sedimentares aluvionares mais ao centro e ao norte da bacia controlados por knickpoints de corredeira sobre o eixo principal do sistema fluvial.
\end{abstract}

Palavras chave: Depósitos sedimentares aluvionares. Captura Fluvial. Rede de Drenagem. Terraços

\section{Introdução}

A formação do Vale do rio de Paraíba do Sul e seu relevo estão relacionados à Evolução da Paisagem Geomorfológica do Planalto Sudeste Brasileiro e suas implicações. Os sedimentos retidos ao longo de suas redes de drenagem representam os sucessivos ciclos de agradação e degradação do relevo que muitos autores identificaram em depósitos fluviais de fundos de vale e nos colúvios sobre as encostas, vistos como processos de evolução da rede de drenagem (LEOPOLD et al., 1964, MOURA, et al. 1991, COELHO NETTO, 1999).

O Planalto Sudeste Brasileiro caracteriza-se por um relevo altamente acidentado que se desenvolve sobre rochas da Faixa Móvel Ribeira, de idade pré-cambriana (de 700 a 450Ma). O processo colisional deste cinturão de dobramentos, levou as unidades litológicas a um alinhamento de orientação NE (HEILBRON et al. 2004), associadas a um alto grau metamórfico na formação de gnaisses e granulitos, além de granitos de ocorrência sin e pós-tectônica. Após tais eventos, a quebra do continente Gondwana e abertura do 
Oceano Atlântico, durante o final do Jurássico e início Cretáceo e seus múltiplos eventos até a consolidação do Rift Continental Sudeste implicou em uma mudança significativa no relevo e, consequentemente, nos seus sistemas de drenagens (RICOMMINI et al., 2010). As reativações de estruturas brasilianas e o soerguimento e abatimento de blocos crustais são algumas das principais características desses eventos tectônicos, que promoveram a reorganização dos sistemas de drenagens e uma nova dinâmica hidro-erosiva de suas bacias.

A presente pesquisa baseia-se na caracterização da dinâmica de evolução da rede de drenagem, associada à influência das características lito-estruturais do substrato geológico, resultante dos eventos tectônicos no médio vale do rio Paraíba do Sul. Os depósitos fluviais e sua distribuição espacial são considerados como evidências de processos evolutivos ocorridos na rede de drenagem (SILVA et. al., 2006). Como representante de tais processos foi escolhido um afluente do rio Paraíba do Sul, cujo sistema fluvial principal é constituído pelas articulações entre o rio Macuco e rio Minerva que apresentam expressivos depósitos fluviais, inclusive em níveis suspensos (terraços fluviais). Tais depósitos marcam uma morfologia de fundo de vales alveolares em grandes porções aplainadas do relevo, seguidas de estrangulamentos ao longo da sua rede drenagem.

\section{Material e Métodos}

Localizada no Planalto Sudeste Brasileiro, a bacia do Rio Minerva situa-se no município de Chiador, no limite da fronteira dos estados de Minas Gerais e Rio de Janeiro. O Rio Minerva é um dos afluentes do rio Paraíba do Sul e possui ao longo da sua rede de drenagem um controle expressivo de knickpoints (níveis de base locais) que se correlacionam com a formação de depósitos sedimentares aluvionares, muitos deles contendo terraços fluviais. Os terraços fluviais podem ser vistos como antigas planícies de inundação, que após um processo de incisão fluvial e rebaixamento do nível de base foram abandonados em níveis topográficos mais elevados.

A pesquisa iniciou-se com o levantamento das bibliografias que tratam dos fenômenos geomorfológicos associados aos modelos de evolução da paisagem, desde as características dos sistemas de drenagem até a sua relação com os depósitos sedimentares. A partir disso, com base dos dados georreferenciados retirados das cartas topográficas de 1:50.000 do IBGE, foi feita a delimitação da bacia de drenagem com recorte espacial da pesquisa por meio do software ArcGis10. As cartas topográficas utilizadas foram Anta, Mar de Espanha, Sapucaia e Três Rios.

Os depósitos sedimentares aluvionares, mais expressivos, foram mapeados ao longo da rede drenagem com a utilização de imagens de satélite em ambiente digital. Após esse mapeamento prévio foram realizados trabalhos de campo para a identificação e caracterização das feições geomorfológicas para uma 


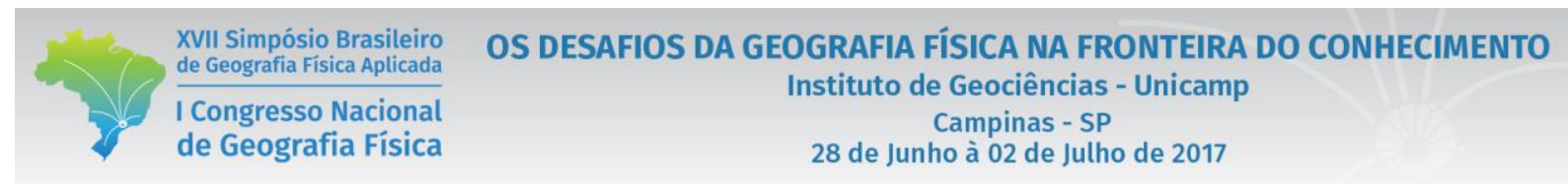

melhor compreensão sobre a dinâmica da rede de drenagem e a evolução de seu relevo, dando destaque para as planícies e terraços sedimentares.

\section{Resultados e Discussões}

No mapa de depósitos sedimentares aluvionares (Figura 1), é possível observar uma disposição de depósitos sedimentares aluvionares mais ao centro e ao norte da bacia o que pode ser explicado pelo controle expressivo que os knickpoints de corredeira exercem sobre o eixo principal do sistema fluvial. Além disso, são nesses depósitos sedimentares aluvionares mais marcantes que foi possível mapear a abundante presença de terraços fluviais, isolados ou contínuos, com elevação entre dois a seis metros de altura em relação à planície atual, caracterizados por depósitos alternados de texturas argilosas e arenosas.

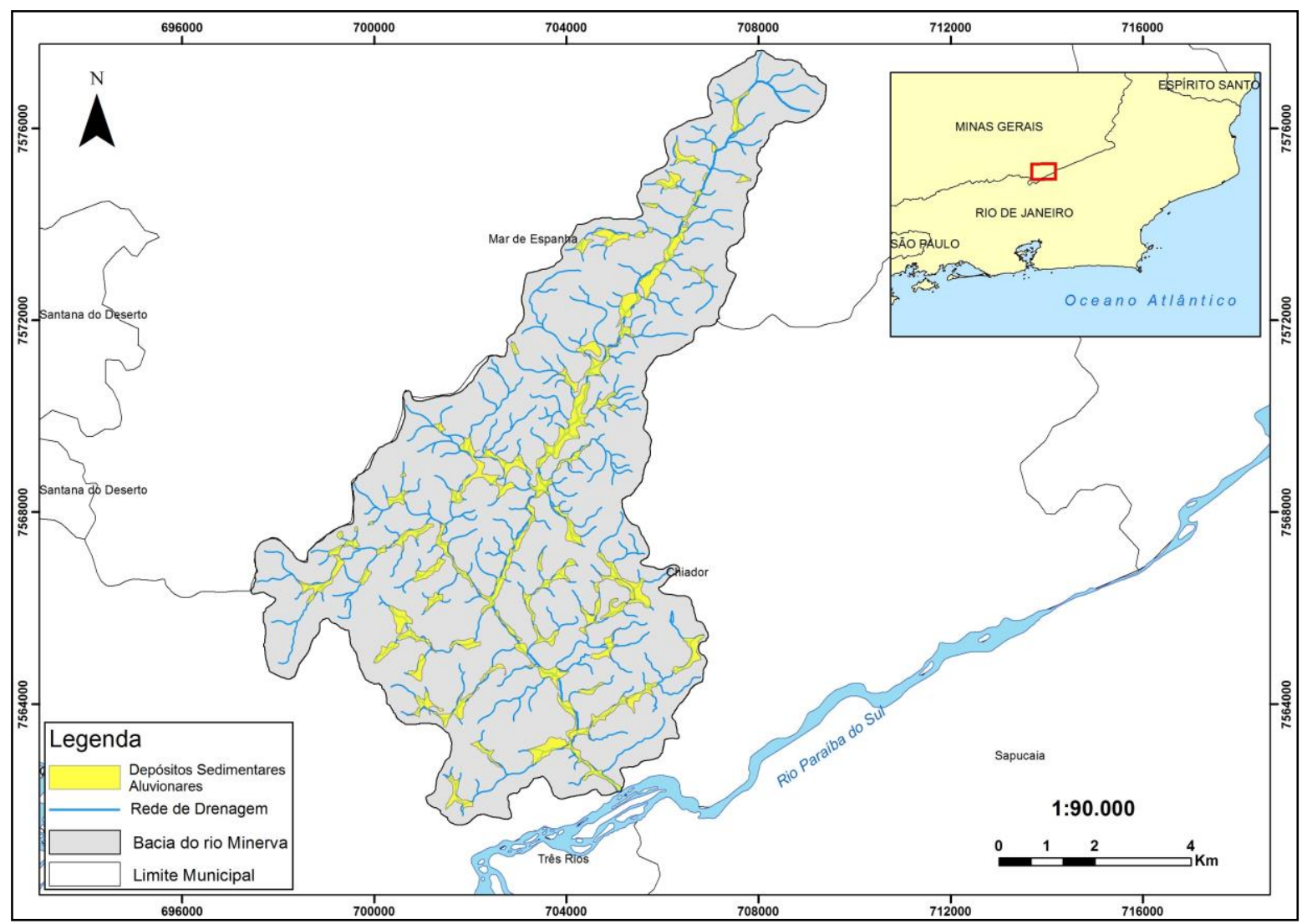

Figura 1: Mapa de distribuição dos depósitos sedimentares aluvionares na bacia do rio Minerva

Constata-se que a evolução da rede de drenagem da bacia estudada tenha relação com os elementos litológicos e suas estruturas dado que os principais trechos dos canais ao longo de toda rede de drenagem alinham-se nas principais direções do substrato geológico. Da mesma forma, contata-se a formação dos 


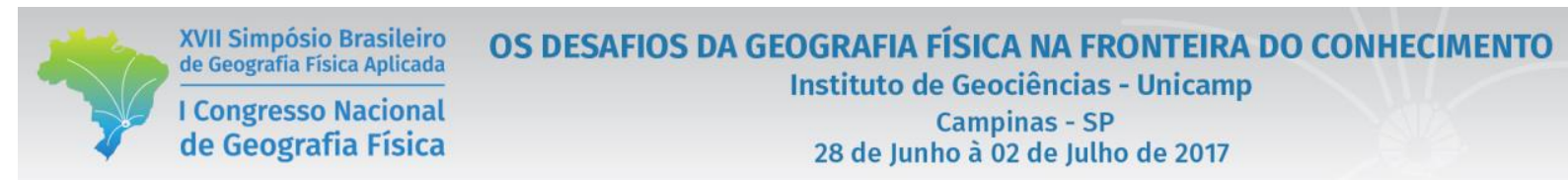

níveis de bases locais (knickpoints) pela resistência litológica. Segundo Bigarella et al. (1965), formam-se ao longo da rede de drenagem depósitos sedimentares aluvionares devido a diminuição de energia de fluxo da água à montante desses knickpoints, que funcionam como pontos de obstrução de sedimentos, fazendo com que se formem seções planas alargadas nos fundos de vale.

Quanto aos aspectos do relevo atual da bacia, pôde-se analisar a ocorrência de colinas na porção central do vale, com drenagens afluentes em vales suspensos, que aparentam processos de capturas de um antigo planalto recuado pela intensa incisão das cabeceiras do rio Minerva. Mais a jusante, outro alvéolo chama atenção em relação ao processo de captura de drenagem, localizado na porção sul da bacia em um divisor de águas com a bacia adjacente do rio Chiador (Figura 2).

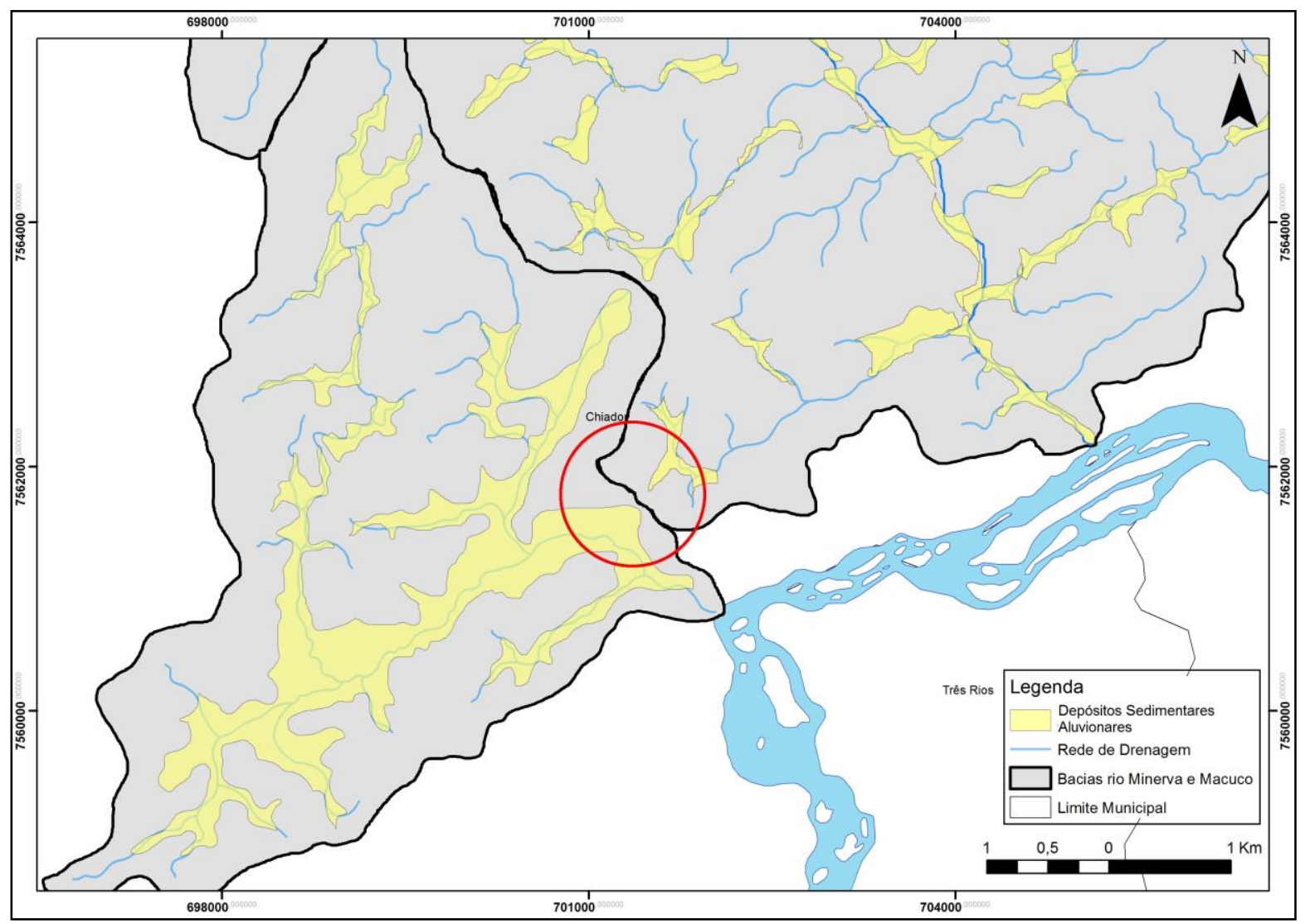

Figura 2: Localização dos sedimentos fluviais em condição de divisor de águas entre as bacias do rio

Macuco/Minerva com o rio Chiador. Destaque no círculo vermelho para área da possível captura.

Uma provável hipótese é, neste caso, que o canal que corria para o Chiador fora abandonado após de um processo de captura fluvial pelo rio Macuco. Tal análise pode ser considerada, uma vez que foi observado nos trabalhos de campo que o divisor de águas, entre estas bacias apresentam um relevo plano característico de fundo de vale, com a presença de sedimentos fluviais. 


\section{Considerações Finais}

A presença de muitos terraços em um trecho da bacia remete a um relevo que sofre constantemente a ação da incisão fluvial. Nesse sentido, a evolução da rede de drenagem da bacia do rio Minerva sofre de um processo de rebaixamento de nível de base que reafeiçoa significantemente as suas feições atuais. A dinâmica fluvial é bastante intensa nesta bacia conforme aumenta a capacidade de incisão, por conta do rebaixamento de níveis de base, novas feições geomorfológicas vão ganhando espaço a medida que nos depósitos sedimentares aluvionares surgem novos terraços. E feito do mesmo processo, as cabeceiras das drenagens adjacentes podem ocorrer a medida que divisores são rompidos por processos de capturas fluviais.

\section{Bibliografia:}

BIGARELLA, J.J. \& MOUSINHO, M.R. Considerações a respeito dos terraços fluviais, rampas de colúvios e várzeas. B. Paran. Geogr., Curitiba, 1965.

COELHO NETTO, A L. Catastrophic Landscape Evolution in a Humid Region (SE Brazil): inheritances from tectonic, climatic and land use induced changes. Supplementidi Geografia Fisica e Dinamica Quaternária, Supp. III, Tomo 3: 21-48. 1999.

HEILBRON, M., PEDROSA-SOARES, A.C., CAMPOS NETO, M.C., SILVA, L.C., TROUW, R.A.J.; JANASI, V.A., Província Maqntiqueira. In: MANTESSO-NETO, V. BARTORELLI, A., CARNEIRO, C.D.R. e BRITONEVES, B.B., Orgs. Geologia do Continente Sul-Americano: evolução da obra de Fernando Flávio Marques de Almeida. São Paulo, Ed.Beca, p.203-236. 2004

LEOPOLD, L. B.; WOLMAN, M. G.; MILLER, J.P. Fluvial Processes. In Geomorphology. San Francisco. W. H. Freeman Co, 1964. p. 522.

MOURA, J.R.S., PEIXOTO,M.N.O.; SILVA,T.M. Geometria do relevo e estratigrafia do quaternário como base à tipologia de cabeceiras de drenagem em anfiteatro -médio vale do rio Paraíba do Sul. Revista Brasileira de Geociências 21 (3): 255-265, 1991

RICCOMINI, C.; GROHMANN, C. H.; SANT'ANNA, L. G.; HIRUMA, S. T. A Captura das Cabeceiras do Rio Tietê pelo Rio Paraíba do Sul. In: MONDENSEI-GAUTTIERI, M. C.; BARTORELLI, A. CARNEIRO, C. R. LISBOA, M. B. A. L. A Obra de Aziz NacibAb'Sáber. São Paulo: Beca-BALL edições, 2010.

SILVA, T.M.; MONTEIRO, H.S.; CRUZ, M.A.; MOURA, J.R.S. Anomalias de drenagem e evolução da paisagem no médio vale do rio Paraíba do Sul (RJ/SP). Anuário do Instituto de Geociências (Rio de Janeiro), v. 29, p. 210-224. 2006. 